\title{
Correction of Iron Deficiency in the Cardiorenal Syndrome
}

\author{
Donald S. Silverberg, ${ }^{1}$ Dov Wexler, ${ }^{2}$ Adrian Iaina, ${ }^{1}$ and Doron Schwartz ${ }^{1}$ \\ ${ }^{1}$ Department of Nephrology, Tel Aviv Sourasky Medical Center, Weizman 6, Tel Aviv 64239, Israel \\ ${ }^{2}$ Department of Cardiology and Heart Failure Unit, Tel Aviv Sourasky Medical Center, Weizman 6, Tel Aviv 64239, Israel
}

Correspondence should be addressed to Donald S. Silverberg, donald@netvision.net.il

Received 9 July 2010; Accepted 23 February 2011

Academic Editor: Anjay Rastogi

Copyright ( 2011 Donald S. Silverberg et al. This is an open access article distributed under the Creative Commons Attribution License, which permits unrestricted use, distribution, and reproduction in any medium, provided the original work is properly cited.

Impaired energy metabolism is a feature of Congestive Heart Failure (CHF). Iron deficiency has been shown to reduce energy production in the cell in animals and humans. Iron deficiency is common in both Chronic Kidney Disease (CKD) and in CHF. Recent studies suggest that iron deficiency is an independent risk factor for mortality in CHF. Studies of correction of the anemia with intravenous (IV) iron in both CKD and CHF have shown an improvement in the anemia and, in some cases, in the renal function as well. Some CHF studies of correction of the iron deficiency have shown an improvement in cardiac function and structure as well as in exercise capacity and quality of life. This occurred independent of whether or not they had anemia, suggesting that the iron deficiency itself may be independently contributing to the worsening of the CHF and CKD. If future long-term studies confirm the safety and efficacy of IV iron in the treatment of iron deficiency in CKD and CHF, this will become a new addition to the therapeutic armamentarium of the cardiorenal syndrome, and parameters of iron deficiency will become part of the routine measurements performed in both CKD and CHF whether or not the patient is anemic.

\section{Introduction}

Impaired energy metabolism is a feature of the Congestive Heart Failure (CHF) syndrome [1]. The failing heart is an energy-starved heart, and energy-sparing treatments such as beta blockers, ACE inhibitors, or Angiotensin II blockers improve the prognosis [1]. Iron metabolism is crucial in all aspects of energy production in the body [2-4] and is particularly important for cells that are characterized by high energy demands such as skeletal myocytes and cardiomyocytes [2-4]. Iron has the ability to shuttle between two oxidative states, (ferric and ferrous iron) which makes it an efficient cofactor for several enzymes and the catalyst of numerous biochemical reactions [2-4]. The ferrous form Fe II can donate electrons while the Fe III form can accept electrons. Iron plays a crucial role in oxygen transport (as a component of hemoglobin $(\mathrm{Hb})$ ), oxygen storage (as a component of myoglobin), and oxidative metabolism (as a component of oxidative enzymes and respiratory chain processes).
It is also involved in the synthesis and degradation of lipids, carbohydrates, DNA, and RNA and in the metabolism of collagen, tyrosine, and catecholamines [2-4].

Therefore, iron deficiency can impair oxidative metabolism, cellular energetics, and cellular immune mechanisms. Iron deficiency in experimental models causes a major disruption in energy production and can lead to cardiac damage and dysfunction $[5,6]$. Even in otherwise normal people, iron deficiency can reduce endurance and optimal energetics of skeletal muscle even if no anemia is present initially [7$10]$.

There is growing evidence that iron deficiency is common in CHF and may contribute to the increased mortality in this condition and that correction of the iron deficiency with IV iron can improve both cardiac and renal function, symptoms of CHF, exercise endurance, inflammation, and quality of life and may reduce hospitalization. However, more studies are needed to confirm this. Thus, correction of iron deficiency could become an important new addition to the treatment of the cardiorenal syndrome. 


\section{Prevalence of Iron Deficiency in CHF with and without Anemia and Its Prognostic Significance}

The prevalence of iron deficiency in CHF depends on how iron deficiency is defined. If merely defined as a \% Transferrin Saturation (\%TSat) of $<16$, it was found in one preliminary study in $78 \%$ of anemic and $61 \%$ of nonanemic CHF patients, whereas if it was defined as a \%TSat of $<16$ and a serum ferritin of $30-100 \mathrm{ug} / \mathrm{L}$, it was found in only $15 \%$ of anemic and $20 \%$ of nonanemic CHF patients [11]. In one study of CHF patients, a low serum iron was found in $31 \%$ of anemics and $7 \%$ of nonanemics, a low serum ferritin in $21 \%$ of anemics and $7 \%$ of nonanemics, and at least one of the two in $43 \%$ of anemics and $15 \%$ of nonanemics [12]. In a study of CHF patients undergoing coronary stenting, $31 \%$ had iron deficiency as judged by a low serum iron and increased Total Iron Binding Capacity. Iron deficiency anemia strongly predicted cardiac mortality [13]. In another study of anemia in CHF, about half the patients had serum iron levels below normal, and the great majority of anemic patients also had an elevated soluble transferrin receptor (a quite dependable measure of iron deficiency) [14]. In a study of anemia in severe CHF, markedly reduced iron stores in the bone marrow were found in $73 \%$ of the cases [15] even though the great majority had a normal serum ferritin level.

In the largest observational study done to date [16], a prospective observational study, 546 patients with stable systolic mild to severe CHF were followed for a mean of $731 \pm$ 350 days. Patients with severe renal disease were excluded and indeed the mean calculated glomerular filtration rate (GFR) was $80.5 \mathrm{~mL} / \mathrm{min} / 1.73 \mathrm{sq} \mathrm{m}$. Iron deficiency was defined as a serum ferritin $<100 \mathrm{ug} / \mathrm{L}$ or $100-300 \mathrm{ug} / \mathrm{L}$ with \%TSat $<20 \%$. The prevalence of iron deficiency was $37 \pm 4 \%$ for the entire population and was $32 \pm 4 \%$ in the nonanemics and $57 \pm 10 \%$ in the anemics (anemia was defined as a $\mathrm{Hb}<12 \mathrm{~g} / \mathrm{dL}$ in women and $<13 \mathrm{~g} / \mathrm{dL}$ in men). Even in those with mild heart failure as judged by NYHA I and II, the frequency of iron deficiency did not drop below $30 \%$. The prevalence of iron deficiency was related to the female sex, the severity of the CHF as judged by the New York Heart Association class (NYHA) and by the Beta Natriuretic Peptide (BNP), and the severity of the inflammatory process as judged by $\mathrm{C}$ Reactive Protein (CRP). In univariate models, the 3-year survival rate was $59 \%$ in the iron deficiency group and $71 \%$ in the noniron deficiency group $(P=.0006)$. In multivariable analysis, iron deficiency was considered an independent predictor of all-cause mortality after adjustment for confounders including anemia and severity of the CHF. The effect was seen as early as 6 months. The inclusion of anemia in the multivariable models did not change significantly the significance suggesting that iron deficiency may be a stronger prognostic indicator of survival than anemia. Thus, iron deficiency, independent of anemia and cardiac function, is related to a poor outcome in CHF.
Therefore absolute iron deficiency (defined as a serum ferritin $<100 \mathrm{ug} / \mathrm{L}$ and $\%$ TSat $<20 \%$ ) or functional iron deficiency (defined as a serum ferritin $>100 \mathrm{ug} / \mathrm{L}$ and \%TSAT $<$ $20 \%$ ) are commonly seen in CHF patients with anemia or even without anemia and are associated with an increased mortality.

\section{Does Correction of the Anemia with Erythropoiesis Stimulating Agents (ESA) in Patients with CHF Improve the CHF?}

Several metaanalyses which included nonplacebo controlled studies, and placebo-controlled studies of ESA along with oral or IV iron have shown improvement in many aspects of $\mathrm{CHF}$ without causing undesirable side effects [17-21]. But all of these studies have been small and/or short term and a total of about only 700 patients in all have been studied. On the other hand, in a larger metaanalysis of ESA treatment in CHF that included the CHF patients in the TREAT study, the Reduce Cardiovascular Events with Aranesp (TREAT) study in diabetics with renal insufficiency, pooled data from 9 placebo-controlled studies enrolling a total of 2,039 anemic CHF patients treated with ESA was associated with a neutral effect on both mortality and nonfatal heart failure events [22]. Therefore, the value of ESA in the anemia of CHF is still uncertain.

\section{Growing Concern about the Safety of ESA}

There is growing concern about the safety of ESA because of the hypertension, increased thrombotic events, and other cardiovascular complications and possible increased cancer risk seen with its use in CKD [23-25] so that there is growing interest in the use of IV iron alone or at least as the first step in the treatment of the anemia of CKD and CHF before an ESA is started.

\section{Does Correction of Iron Deficiency in Patients with CHF Improve the CHF?}

Six studies where intravenous (IV) iron has been used in iron-deficient CHF patients have been performed, but only two were placebo-controlled double blind studies $[26,27]$.

In one of these two studies [26], a single center study, 40 patients received either IV iron as iron sucrose (Venofer, Vifor Int Zurich) $200 \mathrm{mg}$ a week for 5 weeks or a placebo infusion. Their $\mathrm{Hb}$ was $<12.5 \mathrm{~d} / \mathrm{gL}$ for men and $<11.5 \mathrm{~g} / \mathrm{dL}$ for women. Their initial serum ferritin was $<100 \mathrm{ng} / \mathrm{mL}$ and/or \%TSat $\leq 20 \%$. At 6 -month followup there was a significant improvement in the $\mathrm{Hb}$ levels, NYHA, Left Ventricular Ejection Fraction (LVEF), 6 minute walk test (6MWT), hospitalization rate, Minnesota Living with Heart Failure Questionnaire Quality of Life (MLHFQ) scale, creatinine clearance, C-Reactive protein, and NT pro BNP, a slowing of the heart rate, and lower diuretic requirements in the treated compared to the control group. 
In the other double blind placebo-controlled study, this one a multicenter study (The FAIR-HF study [27]), the patients were randomly assigned to IV ferric carboxylase $200 \mathrm{mg}$ (Vifor Int Zurich) versus matching control in a 2:1 ratio. A total of 459 subjects with chronic left ventricular systolic dysfunction were studied. Their initial serum ferritin was $<100 \mathrm{ug} / \mathrm{L}$ or $100-299 \mathrm{ug} / \mathrm{L}$ if $\%$ TSat was $<20 \%$. The mean initial $\mathrm{Hb}$ was between 9.5 and $13.0 \mathrm{~g} / \mathrm{dL}$. The exclusion criteria were uncontrolled hypertension, other significant heart disease, or impaired liver or renal function. They were given enough iron to maintain the \%TSat at 25$45 \%$ and serum ferritin at $400-800 \mathrm{ng} / \mathrm{mL}$. The primary end points were patient self assessment and investigator-assessed NYHA at 6 months. Secondary end points were 6-minute walk and quality of life (QOL) as assessed by the Kansas City Cardiomyopathy questionnaire and the European EQ 5D QOL visual analogue scale. Safety outcomes included hospitalizations and death. The initial $\mathrm{Hb}$ level was $11.9 \mathrm{~g} / \mathrm{dL}$, mean serum ferritin 50-60 ug/mL, and mean transferrin saturation $17 \%$. At week 24 in the IV iron group the serum ferritin had increased to $313 \pm 13$ versus $74 \pm 8 \mathrm{ng} / \mathrm{mL}$. \%TSat to $29 \pm 1$ versus $19 \pm 1 \%$ and $\mathrm{Hb}$ to $13.0 \pm 0.1$ versus $12.5 \pm 0.1 \mathrm{~g} / \mathrm{dL}$. All these were significant differences from placebo. The use of IV iron was associated with significant improvements in NYHA functional class, 6-minute walk distance (mean study effect $35.8 \mathrm{~m}$ ) EQ5 patient global assessment scale, and Kansas City QOL scale. Renal function improved significantly only in the treated group. At 4 weeks the difference in GFR between the active treatment and placebo was $2.5 \pm 1.5 \mathrm{~mL} / \mathrm{min} / 1.73 \mathrm{sqm}$, at 12 weeks it was $3.0 \pm 1.3$, and at 24 weeks it was $4.0 \pm 1.7 \mathrm{~mL} / \mathrm{min} / 1.73 \mathrm{sqm}$. The magnitude of all the treatment effects did not differ in subjects with or without anemia (defined as a $\mathrm{Hb} \leq$ $12 \mathrm{~g} / \mathrm{dL}$ ). The treatment effects were also not related to the initial age, presence of diabetes, initial severity of the CHF, renal function, or ferritin levels. Although there was no difference in first hospitalization for cardiovascular causes or death in the treated and nontreated, there was a trend to improvement in the two. There was no evidence of any adverse effects of the IV treatment compared to placebo. The improvements compared to controls were seen quite rapidly, even within the first month. The fact that the improvement was similar in the treated group unrelated to the initial $\mathrm{Hb}$ suggests that part of the effect of the IV iron might have been due to its direct effect on body tissues.

In the Ferric Iron Sucrose in Heart Failure study (FERRIC-HF) [28], a randomized open label observer blind study lasting 4 months in 35 patients with CHF who were either anemic $(\mathrm{Hb}<12.5 \mathrm{~g} / \mathrm{dL})$ or non-anemic $(\mathrm{Hb} 12.5-$ $14.5 \mathrm{~g} / \mathrm{dL}$ ) but all of whom were iron deficient, patients were assigned in a $2: 1$ ratio to receive 16 weeks of IV iron sucrose (Venofer) or to a control group. Unlike the previous 2 studies, treatment did not result in a significant improvement in $\mathrm{Hb}$ levels. Nevertheless there was a trend toward an improvement in exercise tolerance as judged by peak $\mathrm{VO} 2$ and a significant increase in peak $\mathrm{VO} 2 / \mathrm{kg}$ in the treated group but not in the control group. There was also a trend toward an increase in absolute exercise duration and percentage change in exercise duration in the iron group but not in the control group. There were significant improvements in NYHA, patient global assessment, MLHFQ quality of life scale, and fatigue score in the iron group. All the changes were more pronounced in the anemic group than the nonanemic group. The heart rate fell in the anemic group only. The changes in peak $\mathrm{VO} 2$ were related to changes in \% TSat but not to $\mathrm{Hb}$ in anemic patients suggesting therefore, as did the previous paper, that the improvement in CHF was due at least partially to the correction of the iron deficiency and not to an increase in $\mathrm{Hb}$.

Bolger et al. [29] treated 16 CHF patients with intravenous iron sucrose (Venofer-Zurich) in an uncontrolled open label study. The $\mathrm{Hb}$ was $<12 \mathrm{~g} / \mathrm{dL}$ and the serum ferritin $<400 \mathrm{ug} / \mathrm{L}$. Patients were treated for 12-17 days and followed for $92 \pm 6$ days. Treatment was associated with an increase in the $\mathrm{Hb}$ level $(11.2 \pm 0.7$ to $12.6 \pm 1.2 \mathrm{~g} / \mathrm{dL})$ and a significant improvement in the NYHA class, MLHFQ score, and 6-min walk distance (6MWD). There was a trend toward improved renal function.

Usmanov et al. [30] treated 32 moderate to severe (NYHA III and IV) CHF patients and moderate renal failure (mean serum creatinine $2.3 \mathrm{mg} / \mathrm{dL}$ ) with IV iron (Venofer) in an uncontrolled study for 26 weeks. The inclusion $\mathrm{Hb}$ was $<11 \mathrm{~g} / \mathrm{dL}$. Iron sucrose was given in a dose of $100 \mathrm{mg} 3$ times a week for 3 weeks and then once weekly for 23 weeks (total dose $3200 \mathrm{mg}$ of iron). The mean $\mathrm{Hb}$ increased from $10.7 \pm 0.4$ to $13.7 \pm 0.4$ in NYHA III and from $9.4 \pm 0.6$ to $12.7 \pm 0.08$ in NYHA IV. The mean serum iron, \%TSat, ferritin were all lower than normal before treatment and increased to normal after treatment. There was a significant improvement in NYHA in the NYHA III group but not in the NYHA IV group. Initially there was evidence of severe cardiac hypertrophy and dilation and reduced LVEF, and these improved after 6 months of IV treatment, but more so in NYHA III than in NYHA IV. There was no change in renal function.

In a sixth study [31] which examined the effect of IV iron in bone marrow-confirmed iron deficiency anemia in severe CHF with anemia, 8 patients were randomly assigned to treatment with IV iron $300 \mathrm{mg}$ once weekly for 6 weeks (total $1800 \mathrm{mg}$ ) and 8 others to the same treatment along with 50 ug darbepoetin once weekly for six weeks. Over the entire 3 months of treatment and followup, the $\mathrm{Hb}$ increased by $2.4 \mathrm{~g} / \mathrm{dL}$ in the IV iron alone group and by $2.8 \mathrm{~g} / \mathrm{dL}$ in the group with both agents. This small study suggests that the IV iron is a major contributor to the anemia. This study and that of Usmanov et al. [30] mentioned above also point out that higher doses of IV iron lead to greater $\mathrm{Hb}$ responses than lower doses, that is, there is a dose response relationship. This has been seen in CKD as well [32].

These studies suggest that the anemia of many CHF patients can be improved by IV iron alone. On the other hand, in several studies of anemia treatment in $\operatorname{CHF}[33,34]$, the use of oral iron in anemic CHF patients for one year was not associated with any increase in $\mathrm{Hb}$ or improvement in any CHF parameters. 


\section{What Are the Causes of Iron Deficiency in CHF?}

6.1. Chronic Kidney Disease (CKD). CKD is associated with reduced production of Erythropoietin (EPO) in the kidney. The renal damage seen in CHF is probably mainly due to reduced renal blood flow caused by the reduced cardiac output causing hypoxic renal damage $[21,35]$.

Iron deficiency is also common in CKD [36-39]. About half the cases of iron deficiency are absolute iron deficiency with low \%TSat and low serum ferritin (usually associated with decreased iron stores), and about half are relative iron deficiency with low \%TSat and normal or elevated serum ferritin (often associated with normal or increased iron stores). The iron deficiency is frequently associated with reduced iron deposits in the bone marrow [39, 40]. Because CKD is an inflammatory condition, increased cytokines may also contribute to the anemia and to the iron deficiency (see below). The use of Erythropoiesis Stimulating Agents (ESAs) in CKD will also rapidly reduce iron stores. The gastrointestinal causes of anemia in CKD are discussed below.

6.2. Elevated Cytokines Causing Abnormalities in EPO and Iron Metabolism. These cytokines are elaborated in $\mathrm{CHF}$ and CKD, especially Tumour Necrosis Factor alpha (TNF $\alpha$ ) and interleukin-6 (IL-6). They can cause four haematological abnormalities $[41,42]$ :

(a) reduced EPO production in the kidney leading to inappropriately low levels in the blood for the degree of anemia present,

(b) reduced erythropoietic response of the bone marrow to ESA,

(c) hepcidin-induced failure of iron absorption from the gut, and

(d) hepcidin-induced trapping of iron in iron stores in the macrophages and hepatocytes.

Hepcidin $[29,30]$ is a protein released from the liver by IL-6. It inhibits the protein ferroportin which is found in the gastrointestinal tract and in macrophages and hepatocytes and is responsible for the release of iron from these three types of cells into the blood. Therefore if ferroportin is inhibited, gastrointestinal iron absorption is diminished, and iron is also not released from its storage in macrophages and hepatocytes. This results in a low serum iron leading to decreased delivery of iron to the bone marrow and therefore iron deficiency anemia, even in the presence of adequate total iron stores, the so-called functional iron deficiency. Since hepcidin is filtered and removed in the kidney, its levels increase in CKD, which can also partly explain the iron deficiency in CKD [43] and in CHF in whom about half the patients have renal insufficiency as judged by a creatinine clearance of $<60 \mathrm{~mL} / \mathrm{min} / 1.73 \mathrm{sqm}$ [44].

6.3. Gastrointestinal Problems. There are many other causes of iron deficiency in CKD including reduced iron intake due to low protein diets and anorexia, gastrointestinal blood loss due to uremia causing platelet dysfunction, as well as esophagitis, gastritis, tumors, platelet inhibitors and anticoagulants [45], and phosphate binders which can also bind iron. It has also been found that proton pump inhibitors such as omeprazole, which are extremely widely used, reduce iron absorption [46]. In addition, CHF itself can cause intestinal cell dysfunction due to bowel edema and other causes [47]. Frequent removal of blood for blood tests may also contribute to the anemia.

Also, as mentioned earlier, both $\mathrm{CKD}$ and $\mathrm{CHF}$ are inflammatory conditions with increased cytokines which can cause hepcidin-induced iron deficiency.

\section{The Cellular Effects of Iron Deficiency}

Iron is indispensable for life, serving as a metal cofactor for many enzymes, either nonheme iron-containing proteins or hemoproteins. Hemoproteins are involved in many crucial biologic functions including oxygen binding (hemoglobins), oxygen metabolism (oxidases, peroxidase, catalases, etc.), and electron transfer (cytochromes). Many nonheme ironcontaining proteins catalyze key reactions involved in energy metabolism and DNA and RNA synthesis. In addition, iron-containing proteins are required for the metabolism of collagen, tyrosine, and catecholamines [2-4].

Experimental studies in animals have shown that severe iron deficiency can cause diastolic dysfunction and heart failure with pulmonary congestion, left ventricular hypertrophy and dilation, cardiac fibrosis, a reduction in the erythropoietin levels and a worsening of the molecular signaling pathways (as measured by cardiac STAT 3 phosphorylation), an increase in the inflammatory cytokine $\mathrm{TNF} \alpha$, and proteinuria [5]. This defect in the molecular signaling pathway in iron deficiency may be critical for the transition from adaptive cardiac hypertrophy to cardiac dysfunction in longterm iron deficiency. In addition, iron deficiency in rat hearts causes mitochondrial ultrastructural aberrations, irregular sarcomere organisation, and release of cytochrome C [6].

Iron may have anti-inflammatory effects. Compared to haemodialysis patients taking EPO alone, those taking EPO and IV iron had lower proinflammatory $\mathrm{TNF} \alpha$ levels and higher anti-inflammatory cytokine IL-4 levels as well as lower levels of total peroxide (a marker of free radical concentration) [48].

\section{Oral versus IV Iron in CKD}

As mentioned earlier, in patients with CKD who are anemic, iron deficiency has been found in at least half the patients using either blood tests [36-39] or bone marrow biopsies $[39,40]$, and IV iron alone may increase the Hb significantly [39, 40, 49-51]. In most studies comparing oral to IV iron in $\mathrm{CKD}, \mathrm{IV}$ iron has been found to produce a greater $\mathrm{Hb}$ response than oral iron with less side effects $[32,50,51]$, and many patients can reach a target $\mathrm{Hb}$ of 11.0 to $12 \mathrm{~g} / \mathrm{dL}$ with this therapy alone and therefore avoid the use of ESA altogether [32, 40,49-51]. Although there has been concern 
about IV iron causing renal disease [52], this has not been confirmed by other studies [32, 39, 40,49-51]. Indeed, in one study renal function in CKD improved in the IV iron group but not in the oral iron group [50]. In most studies comparing oral to IV iron in CKD, IV iron has been found to produce a greater $\mathrm{Hb}$ response with less side effects [51]. As mentioned above, in several studies of anemia treatment in $\mathrm{CHF}[33,34]$, the use of oral iron in anemic CHF patients for one year was not associated with any increase in $\mathrm{Hb}$ or improvement in any CHF parameters.

\section{Iron Deficiency and Thrombocytosis}

The incidence of venous thromboembolism is greatly increased in CHF [53], and indeed CHF is considered to be a hypercoagulable state [54]. Could iron deficiency in these CHF patients be one cause of this? Iron deficiency can cause thrombocytosis [55] which can lead to increased thrombosis, atherosclerosis, and increased mortality $[56,57]$. Correction of the iron deficiency with IV iron in EPO-treated dialysis patients reduced the platelet count significantly [58]. This may be important, since thrombocytosis may be one of the missing links in causing the increased incidence of cardiovascular effects of EPO in CKD $[56,57]$ and in cancer $[59,60]$. High doses of EPO in CKD are associated with more iron deficiency, more severe thrombocytosis, and increased mortality [56, 57]. Iron deficiency also increases oxidative stress [61].

\section{The Administration of Iron in Anemic and Nonanemic People}

Beutler showed over fifty years ago that iron deficiency can negatively affect enzymes throughout the body with or even without actual anemia being present [7]. He also showed in a randomised double-blind placebo-controlled crossover study that oral iron can improve fatigue in anemic and also in nonanemic iron deficient women [7], and this has been subsequently confirmed by others [8-10]. All these studies suggest that iron has a specific effect on the cells in addition to its ability to make hemoglobin.

\section{What Assays Predict the Response to IV Iron?}

The two commonly used tests to detect iron deficiency are a low \% Transferrin Saturation (\%TSat) and a low serum ferritin. But though they are low in absolute iron deficiency where iron stores are low, the \%TSat may become low but the serum ferritin high in the presence of inflammation and therefore may not reflect iron status accurately. This is the socalled anemia of chronic disease. In fact, iron stores may be elevated in inflammation in the face of a low \% TSat, and the serum ferritin may be elevated in the presence of depleted iron stores. There is no test that can predict with great accuracy the degree of response to IV iron in patients taking ESA in CKD $[39,62,63]$. However, generally in CKD the $\%$ TSat is a better predictor than ferritin, and the reticulocyte
$\mathrm{Hb}$ is better than \%TSat $[62,63]$, but the differences are probably not large enough to be clinically useful.

\section{Concerns about the Safety of Iron}

There is some evidence in hemodialysis patients that IV iron treatment is associated with a lower mortality [6466]. Recently, in CKD patients not on dialysis, it was found that the lower the \%TSat the higher the mortality, again raising the possibility that iron deficiency may be a common and reversible cause of severe cardiovascular disease [67]. However, IV iron can cause oxidative stress [68], and therefore long-term controlled studies of IV iron are needed to evaluate the effects of IV iron in CKD, as in CHF. Although there has been concern about increased iron stores being associated with increased risk of coronary heart disease [69] this has not been confirmed by others [70, 71], and the issue is still controversial. But the implications of the presence of iron deficiency in CHF are enormous since, as mentioned above, a high percentage of patients with $\mathrm{CHF}$, whether anemic or not anemic, have true or functional iron deficiency. If correction of this iron deficiency proves both safe and effective, this could be a new and useful addition to the treatment of CHF.

\section{How Does Anemia Cause or Worsen CHF?}

It appears that anemia can exacerbate heart failure through a vicious circle in which tissue hypoxia and release of nitric oxide causes peripheral vasodilation which leads to decreased blood pressure which then causes increased sympathetic activation, renal vasoconstriction, reduced renal function, and activation of the renin-angiotensin aldosterone system $[21,35]$. This in turn leads to fluid retention, left ventricular hypertrophy and dilatation, worsening heart failure, release of $\mathrm{BNP}$ arising from stress on the myocardium, and, to complete the vicious circle, further anemia.

\section{The Cardiorenal Anemia Syndrome}

About 10 years ago, we described the Cardio Renal Anemia syndrome (CRA syndrome) [72]. Our hypothesis was that there is a vicious circle operating between Congestive Heart Failure (CHF), Chronic Renal Failure, and anemia where each might cause or worsen the other. The correction of anemia was a major part of this vicious circle in the reduction of the severity of the CHF. In view of the possible independent association of iron deficiency and cardiac failure, renal failure, and anemia we now suggest renaming the syndrome the CRAID syndrome, the Cardio Renal Anemia Iron Deficiency Syndrome.

\section{Conclusion}

It is daunting to consider that the use of something as simple as IV iron in CHF patients with absolute or functional iron deficiency may have an important role to play in the treatment of a large percentage of CHF patients, both anemic 
and nonanemic and with or without CKD. Clearly, long-term adequately-powered placebo-controlled studies of IV iron in CHF with hard endpoints are needed. In the meantime, in the assessment of patients with CKD and/or CHF, the laboratory markers of iron deficiency should be routinely measured. Faced with a patient with absolute or functional iron deficiency with or without anemia who has CHF with or without CKD, it is the authors' opinion that a trial of IV iron might reduce significantly the severity of these conditions and should be administered before an ESA is started.

\section{References}

[1] S. Neubauer, "The failing heart—an engine out of fuel," The New England Journal of Medicine, vol. 356, no. 11, pp. 11401151, 2007.

[2] P. Ponka, "Cellular iron metabolism," Kidney International, Supplement, vol. 55, no. 69, pp. S2-S11, 1999.

[3] G. Cairo, F. Bernuzzi, and S. Recalcati, "A precious metal: iron, an essential nutrient for all cells," Genes and Nutrition, vol. 1, pp. 25-40, 2006.

[4] G. J. Anderson and C. D. Vulpe, "Mammalian iron transport," Cellular and Molecular Life Sciences, vol. 66, no. 20, pp. 32413261, 2009.

[5] F. Dong, X. Zhang, B. Culver, H. G. Chew, R. O. Kelley, and J. Ren, "Dietary iron deficiency induces ventricular dilation, mitochondrial ultrastructural aberrations and cytochrome $\mathrm{c}$ release: involvement of nitric oxide synthase and protein tyrosine nitration," Clinical Science, vol. 109, no. 3, pp. 277286, 2005.

[6] Y. Naito, T. Tsujino, M. Matsumoto, T. Sakoda, M. Ohyanagi, and T. Masuyama, "Adaptive response of the heart to longterm anemia induced by iron deficiency," American Journal of Physiology, vol. 296, no. 3, pp. H585-H593, 2009.

[7] E. Beutler, "History of iron in medicine," Blood Cells, Molecules \& Diseases, vol. 29, no. 3, pp. 297-308, 2002.

[8] J. D. Haas and T. Brownlie, "Iron deficiency and reduced work capacity: a critical review of the research to determine a causal relationship," Journal of Nutrition, vol. 131, no. 2, pp. 676S688S, 2001.

[9] T. Brownlie, V. Utermohlen, P. S. Hinton, C. Giordano, and J. D. Haas, "Marginal iron deficiency without anemia impairs aerobic adaptation among previously untrained women," American Journal of Clinical Nutrition, vol. 75, no. 4, pp. 734742, 2002.

[10] F. Verdon, B. Burnand, C. L. Fallab Stubi et al., "Iron supplementation for unexplained fatigue in non-anaemic women: double blind randomised placebo controlled trial," British Medical Journal, vol. 326, no. 7399, pp. 1124-1126, 2003.

[11] C. L. Murphy, R. J. Fitzimmons, A. J. Jardine et al., "Routine assessment of iron status in all patients with heart failure may identify those at risk of developing anemia," European Journal of Heart Failure, vol. 61, p. 103, 2007.

[12] R. de Silva, A. S. Rigby, K. K. A. Witte et al., "Anemia, renal dysfunction, and their interaction in patients with chronic heart failure," American Journal of Cardiology, vol. 98, no. 3, pp. 391-398, 2006.

[13] A. Varma, D. L. Appleton, A. Nusca et al., "Iron deficiency anemia and cardiac mortality in patients with left ventricular systolic dysfunction undergoing coronary stenting," Minerva Cardioangiologica, vol. 58, no. 1, pp. 1-10, 2010.
[14] C. Opasich, M. Cazzola, L. Scelsi et al., "Blunted erythropoietin production and defective iron supply for erythropoiesis as major causes of anaemia in patients with chronic heart failure," European Heart Journal, vol. 26, no. 21, pp. 22322237, 2005.

[15] J. N. Nanas, C. Matsouka, D. Karageorgopoulos et al., "Etiology of anemia in patients with advanced heart failure," Journal of the American College of Cardiology, vol. 48, no. 12, pp. 2485-2489, 2006.

[16] E. A. Jankowska, P. Rozentryt, A. Witkowska et al., "Iron deficiency: an ominous sign in patients with systolic chronic heart failure," European Heart Journal, vol. 31, no. 15, pp. 1872-1880, 2010.

[17] F. Tehrani, P. Dhesi, D. Daneshvar et al., "Erythropoiesis stimulating agents in heart failure patients with anemia: a metaanalysis," Cardiovascular Drugs and Therapy, vol. 23, no. 6, pp. 511-518, 2009.

[18] B. Jin, X. Luo, H. Lin, J. Li, and H. Shi, "A meta-analysis of erythropoiesis-stimulating agents in anaemic patients with chronic heart failure," European Journal of Heart Failure, vol. 12, no. 3, pp. 249-253, 2010.

[19] P. van der Meer, H. F. Groenveld, J. L. Januzzi, and D. J. van Veldhuisen, "Erythropoietin treatment in patients with chronic heart failure: a meta-analysis," Heart, vol. 95, no. 16, pp. 1309-1314, 2009.

[20] K. Ngo, D. Kotecha, J. A. Walters et al., "Erythropoiesisstimulating agents for anaemia in chronic heart failure patients," Cochrane Database of Systematic Reviews, no. 1, Article ID CD007613, 2010.

[21] D. S. Silverberg, D. Wexler, A. Iaina, and D. Schwartz, "The correction of anemia in patients with the combination of chronic kidney disease and congestive heart failure may prevent progression of both conditions," Clinical and Experimental Nephrology, vol. 13, no. 2, pp. 101-106, 2009.

[22] A. Desai, E. Lewis, S. Solomon, J. J.V. McMurray, and M. Pfeffer, "Impact of erythropoiesis-stimulating agents on morbidity and mortality in patients with heart failure: an updated, post-TREAT meta-analysis," European Journal of Heart Failure, vol. 12, no. 9, pp. 936-942, 2010.

[23] E. F. Unger, A. M. Thompson, M. J. Blank, and R. Temple, "Erythropoiesis-stimulating agents-time for a reevaluation," The New England Journal of Medicine, vol. 362, no. 3, pp. 189192, 2010.

[24] D. Goldsmith, "2009: a requiem for rHuEPOs—but should we nail down the coffin in 2010?" Clinical Journal of the American Society of Nephrology, vol. 5, no. 5, pp. 929-935, 2010.

[25] A. K. Singh, "Does TREAT give the boot to ESAs in the treatment of CKD anemia?" Journal of the American Society of Nephrology, vol. 21, no. 1, pp. 2-6, 2010.

[26] J. E. Toblli, A. Lombraña, P. Duarte, and F. Di Gennaro, "Intravenous iron reduces NT-pro-brain natriuretic peptide in anemic patients with chronic heart failure and renal insufficiency," Journal of the American College of Cardiology, vol. 50, no. 17, pp. 1657-1665, 2007.

[27] S. D. Anker, J. C. Colet, G. Filippatos et al., "Ferric carboxymaltose in patients with heart failure and iron deficiency," The New England Journal of Medicine, vol. 361, no. 25, pp. 24362448, 2009.

[28] D. O. Okonko, A. Grzeslo, T. Witkowski et al., "Effect of intravenous iron sucrose on exercise tolerance in anemic and nonanemic patients with symptomatic chronic heart failure and iron deficiency," Journal of the American College of Cardiology, vol. 51, no. 2, pp. 103-112, 2008. 
[29] A. P. Bolger, F. R. Bartlett, H. S. Penston et al., "Intravenous iron alone for the treatment of anemia in patients with chronic heart failure," Journal of the American College of Cardiology, vol. 48, no. 6, pp. 1225-1227, 2006.

[30] R. I. Usmanov, E. B. Zueva, D. S. Silverberg, and M. Shaked, "Intravenous iron without erythropoietin for the treatment of iron deficiency anemia in patients with moderate to severe congestive heart failure and chronic kidney insufficiency," Journal of Nephrology, vol. 21, no. 2, pp. 236-242, 2008.

[31] S. G. Drakos, M. I. Anastasiou-Nana, K. G. Malliaras, and J. N. Nanas, "Anemia in chronic heart failure," Congestive Heart Failure, vol. 15, no. 2, pp. 87-92, 2009.

[32] B. Rozen-Zvi, A. Gafter-Gvili, M. Paul, L. Leibovici, O. Shpilberg, and U. Gafter, "Intravenous versus oral iron supplementation for the treatment of anemia in CKD: systematic review and meta-analysis," American Journal of Kidney Diseases, vol. 52, no. 5, pp. 897-906, 2008.

[33] A. Palazzuoli, D. Silverberg, F. Iovine et al., "Erythropoietin improves anemia exercise tolerance and renal function and reduces B-type natriuretic peptide and hospitalization in patients with heart failure and anemia," American Heart Journal, vol. 152, no. 6, pp. 1096-e9, 2006.

[34] A. Palazzuoli, D. S. Silverberg, F. Iovine et al., "Effects of $\beta$-erythropoietin treatment on left ventricular remodeling, systolic function, and B-type natriuretic peptide levels in patients with the cardiorenal anemia syndrome," American Heart Journal, vol. 154, no. 4, pp. 645e9-645e15, 2007.

[35] I. S. Anand, "Anemia and chronic heart failure. Implications and treatment options," Journal of the American College of Cardiology, vol. 52, no. 7, pp. 501-511, 2008.

[36] C. Y. Hsu, C. E. McCulloch, and G. C. Curhan, "Iron status and hemoglobin level in chronic renal insufficiency," Journal of the American Society of Nephrology, vol. 13, no. 11, pp. 2783-2786, 2002.

[37] F. Valderrábano, W. H. Hörl, I. C. Macdougall, J. Rossert, B. Rutkowski, and J. P. Wauters, "PRE-dialysis survey on anaemia management," Nephrology Dialysis Transplantation, vol. 18, no. 1, pp. 89-100, 2003.

[38] S. Fishbane, S. Pollack, H. I. Feldman, and M. M. Joffe, "Iron indices in chronic kidney disease in the National Health and Nutritional Examination Survey 1988-2004," Clinical Journal of the American Society of Nephrology, vol. 4, no. 1, pp. 57-61, 2009.

[39] S. Stancu, A. Stanciu, A. Zugravu et al., "Bone marrow iron, iron indices, and the response to intravenous iron in patients with non-dialysis-dependent CKD," American Journal of Kidney Diseases, vol. 55, no. 4, pp. 639-647, 2010.

[40] L. Gotloib, D. Silverberg, R. Fudin, and A. Shostak, "Iron deficiency is a common cause of anemia in chronic kidney disease and can often be corrected with intravenous iron," Journal of Nephrology, vol. 19, no. 2, pp. 161-167, 2006.

[41] E. Nemeth, "Iron regulation and erythropoiesis," Current Opinion in Hematology, vol. 15, no. 3, pp. 169-175, 2008.

[42] G. Weiss, "Iron metabolism in the anemia of chronic disease," Biochimica et Biophysica Acta, vol. 1790, no. 7, pp. 682-693, 2009.

[43] D. R. Ashby, D. P. Gale, M. Busbridge et al., "Plasma hepcidin levels are elevated but responsive to erythropoietin therapy in renal disease," Kidney International, vol. 75, no. 9, pp. 976-981, 2009.

[44] C. Ronco, P. A. McCullough, S. D. Anker et al., "Cardiorenal syndromes: an executive summary from the consensus conference of the acute dialysis quality initiative (ADQI)," Contributions to Nephrology, vol. 165, pp. 54-67, 2010.
[45] S. Flint, E. Taylor, J. Beavis, G. J. Becker, and E. Pedagogos, "Increased iron requirement in hemodialysis patients on antiplatelet agents or warfarin," Nephron Clinical Practice, vol. 113, no. 1, pp. c38-c45, 2009.

[46] C. Hutchinson, C. A. Geissler, J. J. Powell, and A. Bomford, "Proton pump inhibitors suppress absorption of dietary nonhaem iron in hereditary haemochromatosis," Gut, vol. 56, no. 9, pp. 1291-1295, 2007.

[47] A. Sandek, M. Rauchhaus, S. D. Anker, and S. von Haehling, "The emerging role of the gut in chronic heart failure," Current Opinion in Clinical Nutrition and Metabolic Care, vol. 11, no. 5, pp. 632-639, 2008.

[48] G. Weiss, E. Meusburger, G. Radacher, K. Garimorth, U. Neyer, and G. Mayer, "Effect of iron treatment on circulating cytokine levels in ESRD patients receiving recombinant human erythropoietin," Kidney International, vol. 64, no. 2, pp. 572-578, 2003.

[49] G. Mircescu, L. Gârneaţă, C. Cǎpuşǎ, and N. Ursea, "Intravenous iron supplementation for the treatment of anaemia in pre-dialyzed chronic renal failure patients," Nephrology Dialysis Transplantation, vol. 21, no. 1, pp. 120-124, 2006.

[50] D. B. van Wyck, M. Roppolo, C. O. Martinez, R. M. Mazey, and S. McMurray, "A randomized, controlled trial comparing IV iron sucrose to oral iron in anemic patients with nondialysisdependent CKD," Kidney International, vol. 68, no. 6, pp. 2846-2856, 2005.

[51] I. C. MacDougall, "Iron supplementation in the non-dialysis chronic kidney disease (ND-CKD) patient: oral or intravenous," Current Medical Research and Opinion, vol. 26, no. 2, pp. 473-482, 2010.

[52] K. Bishu and R. Agarwal, "Acute injury with intravenous iron and concerns regarding long-term safety," Clinical Journal of the American Society of Nephrology, vol. 1, supplement 1, pp. S19-S23, 2006.

[53] E. S. Darze, A. L. Latado, A. G. Guimarães et al., "Incidence and clinical predictors of pulmonary embolism in severe heart failure patients admitted to a coronary care unit," Chest, vol. 128, no. 4, pp. 2576-2580, 2005.

[54] D. Imberti, M. Giorgi Pierfranceschi, M. Falciani, and D. Prisco, "Venous thromboembolism prevention in patients with heart failure: an often neglected issue," Pathophysiology of Haemostasis and Thrombosis, vol. 36, no. 2, pp. 69-74, 2008.

[55] I. Kuku, E. Kaya, S. Yologlu, R. Gokdeniz, and A. Baydin, "Platelet counts in adults with iron deficiency anemia," Platelets, vol. 20, no. 6, pp. 401-405, 2009.

[56] E. Streja, C. P. Kovesdy, S. Greenland et al., "Erythropoietin, iron depletion, and relative thrombocytosis: a possible explanation for hemoglobin-survival paradox in hemodialysis," American Journal of Kidney Diseases, vol. 52, no. 4, pp. 727736, 2008.

[57] L. A. Szczech, H. X. Barnhart, J. K. Inrig et al., "Secondary analysis of the CHOIR trial epoetin- $\alpha$ dose and achieved hemoglobin outcomes," Kidney International, vol. 74, no. 6, pp. 791-798, 2008.

[58] N. V. Dahl, D. H. Henry, and D. W. Coyne, "Thrombosis with erythropoietic stimulating agents-does iron-deficient erythropoiesis play a role?" Seminars in Dialysis, vol. 21, no. 3, pp. 210-211, 2008.

[59] J. Bohlius, K. Schmidlin, C. Brillant et al., "Recombinant human erythropoiesis-stimulating agents and mortality in patients with cancer: a meta-analysis of randomised trials," The Lancet, vol. 373, no. 9674, pp. 1532-1542, 2009. 
[60] C. L. Bennett, S. M. Silver, B. Djulbegovic et al., "Venous thromboembolism and mortality associated with recombinant erythropoietin and darbepoetin administration for the treatment of cancer-associated anemia," Journal of the American Medical Association, vol. 299, no. 8, pp. 914-924, 2008.

[61] E. Nagababu, S. Gulyani, C. J. Earley, R. Cutler, M. Mattson, and J. Rifkind, "Iron-deficiency anaemia enhances red blood cell oxidative stress," Free Radical Research, vol. 42, no. 9, pp. 824-829, 2008.

[62] S. Stancu, L. Bârsan, A. Stanciu, and G. Mircescu, "Can the response to iron therapy be predicted in anemic nondialysis patients with chronic kidney disease?" Clinical Journal of the American Society of Nephrology, vol. 5, no. 3, pp. 409-416, 2010.

[63] A. K. Singh, D. W. Coyne, W. Shapiro, and A. R. Rizkala, "Predictors of the response to treatment in anemic hemodialysis patients with high serum ferritin and low transferrin saturation," Kidney International, vol. 71, no. 11, pp. 11631171, 2007.

[64] H. I. Feldman, M. Joffe, B. Robinson et al., "Administration of parenteral iron and mortality among hemodialysis patients," Journal of the American Society of Nephrology, vol. 15, no. 6, pp. 1623-1632, 2004.

[65] K. Kalantar-Zadeh, D. L. Regidor, C. J. McAllister, B. Michael, and D. G. Warnock, "Time-dependent associations between iron and mortality in hemodialysis patients," Journal of the American Society of Nephrology, vol. 16, no. 10, pp. 3070-3080, 2005.

[66] V. E. Pollak, J. A. Lorch, R. Shukla, and S. Satwah, "The importance of iron in long-term survival of maintenance hemodialysis patients treated with epoetin-alfa and intravenous iron: analysis of 9.5 years of prospectively collected data," BMC Nephrology, vol. 10, no. 1, article 6, 2009.

[67] C. P. Kovesdy, W. Estrada, S. Ahmadzadeh, and K. KalantarZadeh, "Association of markers of iron stores with outcomes in patients with nondialysis-dependent chronic kidney disease," Clinical Journal of the American Society of Nephrology, vol. 4, no. 2, pp. 435-441, 2009.

[68] K. L. Kuo, S. C. Hung, Y. H. Wei, and D. C. Tarng, "Intravenous iron exacerbates oxidative DNA damage in peripheral blood lymphocytes in chronic hemodialysis patients," Journal of the American Society of Nephrology, vol. 19, no. 9, pp. 1817-1826, 2008.

[69] J. L. Sullivan, "Iron and the sex difference in heart disease risk," The Lancet, vol. 1, no. 8233, pp. 1293-1294, 1981.

[70] C. T. Sempos, "Do body iron stores increase the risk of developing coronary heart disease?" American Journal of Clinical Nutrition, vol. 76, no. 3, pp. 501-503, 2002.

[71] J. Danesh and P. Appleby, "Coronary heart disease and iron status: meta-analyses of prospective studies," Circulation, vol. 99, no. 7, pp. 852-854, 1999.

[72] D. S. Silverberg, D. Wexler, M. Blum, and A. Iaina, “The cardio renal anemia syndrome: correcting anemia in patients with resistant congestive heart failure can improve both cardiac and renal function and reduce hospitalizations," Clinical Nephrology, vol. 60, no. 1, pp. S93-S102, 2003. 


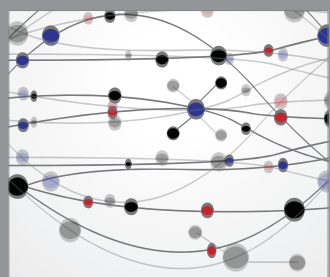

The Scientific World Journal
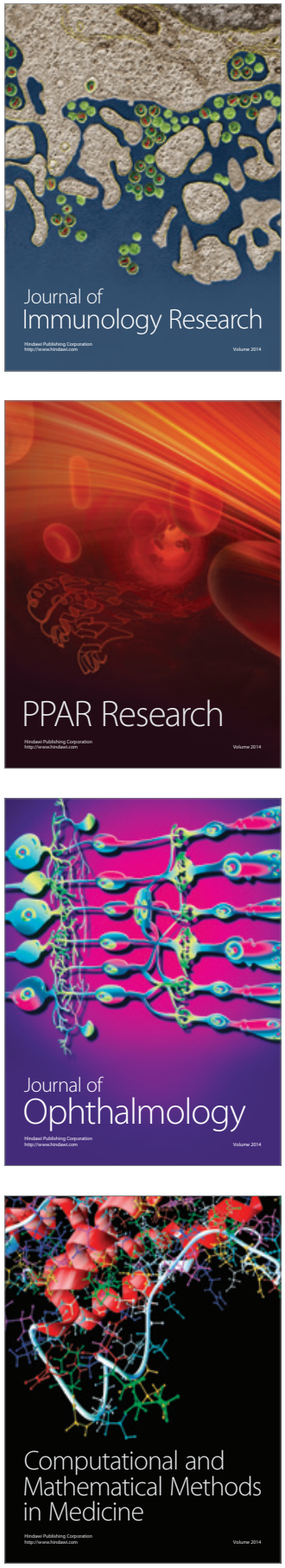

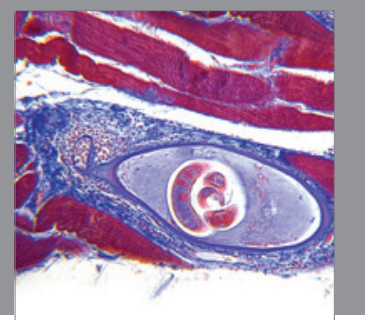

Gastroenterology

Research and Practice
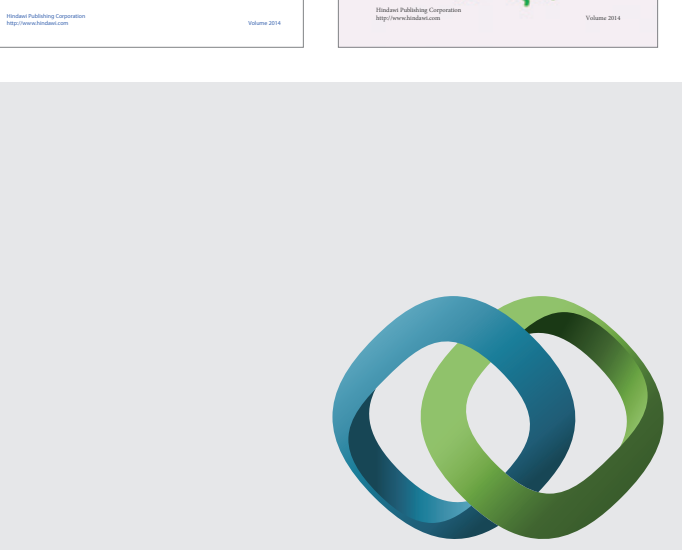

\section{Hindawi}

Submit your manuscripts at

http://www.hindawi.com
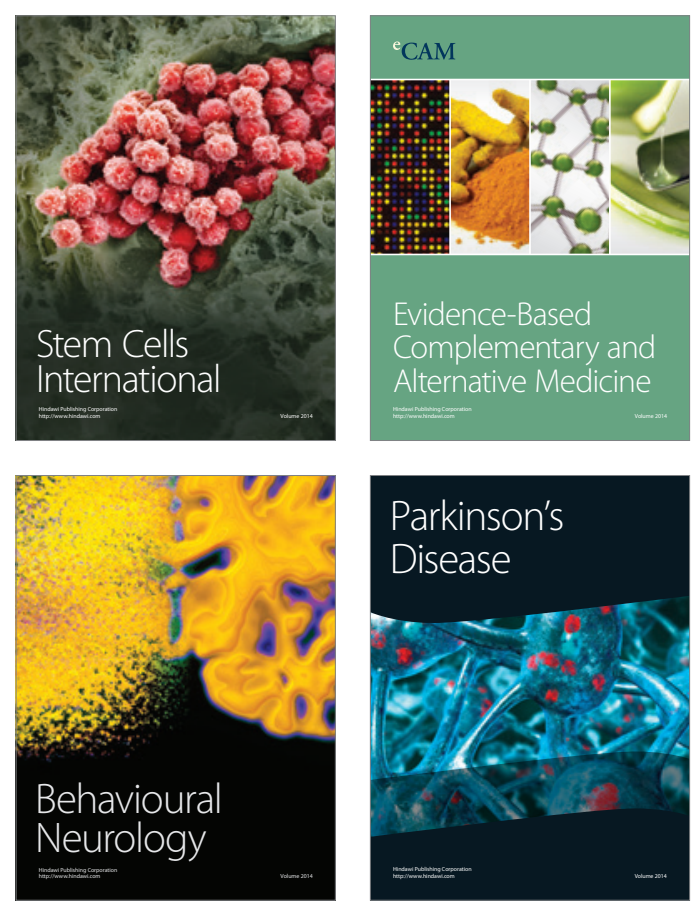

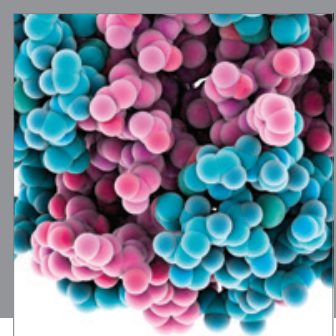

Journal of
Diabetes Research

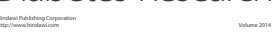

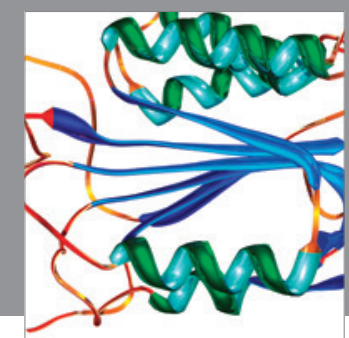

Disease Markers
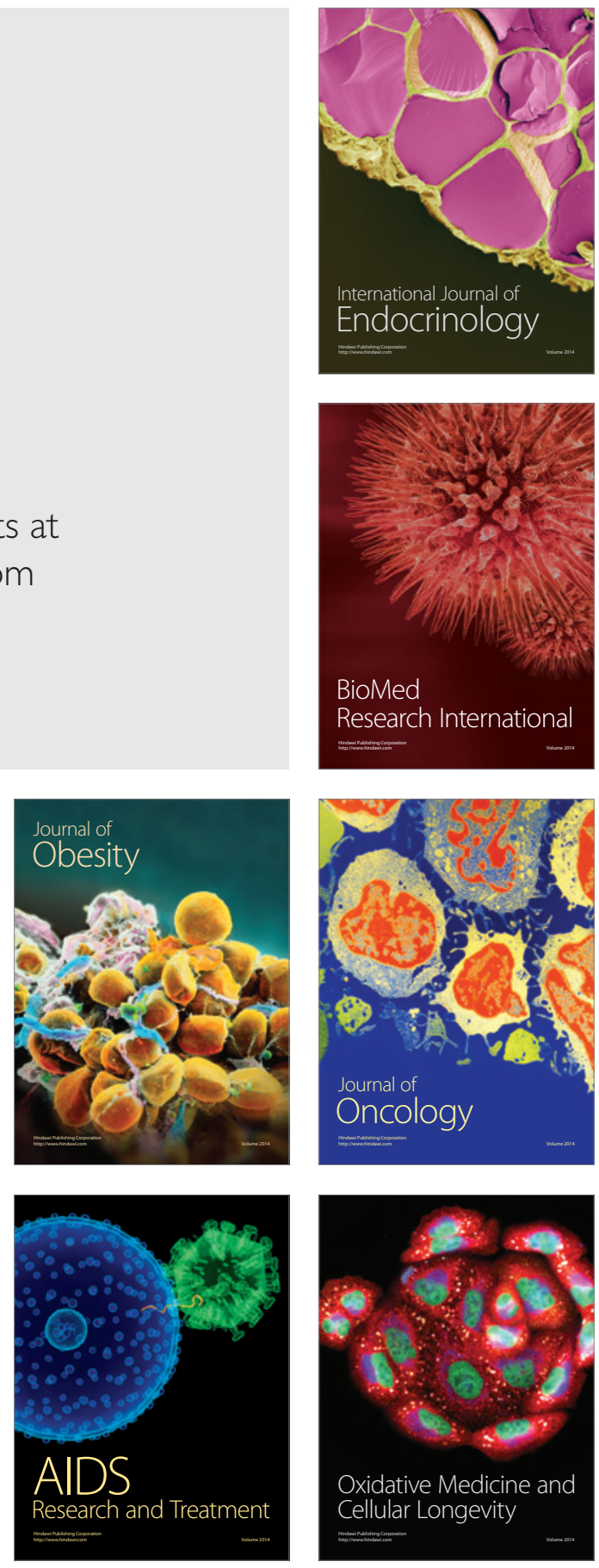